\title{
Conceptual Design of a Thermal Process Plant Weblab
}

\author{
http://dx.doi.org/10.3991/ijoe.v8iS4.2275 \\ M. T. C. de Siqueira, M. L. D. dos Santos, L. A. Mendes \\ Pontificial Catholic University of Parana (PUC/PR), Curitiba, Brazil.
}

\begin{abstract}
Weblabs, or remote experimentation laboratories, make possible carrying out real-time experiments through the internet by using integrated laboratorial systems, software, hardware and multimedia resources, having important applications in engineering education and research teams cooperation. This paper presents the conceptual design of a Weblab for a thermal process plant, based on the systematic model for planning and development of Weblabs. Its approach comprises three layers (physical system, hardware and software), being prescribed the following steps: definition of requirements; system technical specification; conceptual synthesis; analysis, simulation and dimensioning; detailing and documentation; integration and start up test. The users (qualitative) and project (technical, quantitative) requirements have been compiled in a previous work through the application of the House of Quality matrix from the QFD method. The functional structure, the morphological chart and the use of Pugh's method to select the best design solution, as well as a description of the developed conceptual solution, are presented. The conceptual solution includes the thermal process plant remote configuration to allow the variation of the experimental setup parameters, offering three variants of control engineering exercises. The presented results provide the basis for the next stage of the Weblab development.
\end{abstract}

Index Terms-Weblab, Conceptual Design, Thermal Process Plant.

\section{INTRODUCTION}

The recent evolution of information and communication technologies made real the possibility of development of new educational processes, with remarkable benefits for students in terms of the distance learning modality. Weblab, or remotely operated laboratory through the Internet, is a system concept that makes possible the use of laboratories in long distance education and, as well, in research cooperation. The use of such systems permits the extension of the use of laboratories located in developed centers to places where the essential infrastructure is not found. Weblabs can assist in collaborative research activities, with the execution of real time experiments, through the proper addition of complimentary devices, hardware, software and networking resources. As references, [1], [2] and [3] can be cited as elaborated projects of Weblabs.

The development of Weblab projects, as is the case of most technical systems, is a better conducted process if systematized through a design methodology. A very applicable methodological proposal includes the steps: task definition, conceptual design, preliminary design and detailed design, as proposed by [4]. Other authors from the engineering design academy have included further steps including more aspects related to product development processes, planning also production, marketing, maintenance and obsolescence [5].

From the academic community it is possible to find several design methodologies to guide de designs teams during the product development process, such as [4], [5], [6], [7], [8], [9] and [10].

These proposals help the project team in anticipating potential problems or errors during the design development, whilst avoiding the resulting high correction costs when they are not detected in the initial stages.

A methodology proposal specifically directed to the Weblab development process was suggested by [11], as a tool to plan and implement Weblabs.

Therefore, the objective of this work was to develop the Weblab conceptual design for a didactic temperature process plant located at the Systems and Automation Laboratory of the Control and Automation Engineering Department of the Pontifical Catholic University of Parana (Brazil). The model 3504 LabVOLT Temperature Process Station, as shown in Fig. 1, is equipped with an electric oven whose operation range is the $20{ }^{\circ} \mathrm{C}$ $-200^{\circ} \mathrm{C}$ interval.

This station contains an oven which can be manually operated as an on-off process, through a $24 \mathrm{Vdc}$ relay, or proportionally, through a 4 to $20 \mathrm{~mA}$ input signal. The plant includes a compressed air input, used in the variation of the process dynamic characteristics, being the air inflow varied by a manual valve. An adjustable damper located by the oven can also used to generate variable disturbances. The process instrumentation comprises a RTD temperature sensor, a capillary bulb thermal switch and a J-type thermocouple. The plant configuration, equipment connections and signal control

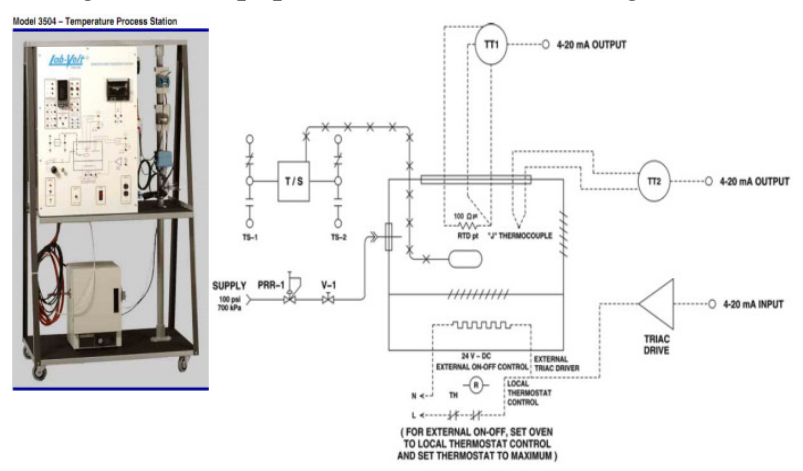

Figure 1. Picture and diagram of the model 3504 Temperature Process Station. 
links will depend on the activity to be carried out, and this is accomplished using the proper connectors located on main control panel.

The didactic activities (experiments) defined for the present Weblab project were: ON-OFF control; PID (proportional, integral, derivative) control; dynamic model identification of the thermal process.

These activities include the following user actions: control signal variation; set-point adjustment; setting of the PID controller parameters; definition of the operation mode (open or closed loop).

Each configuration that must be set up for the remote operation of the didactic activities requires actions on the real system of the temperature plant, which are carried out by specific actuators specially designed for these purposes.

\section{DESIGN METHODOLOGY}

Usually, a product development process is characterized by the participation of an integrated project team through activities and steps carried out in a structured way. At the initial stages, requirements are collected in order to well define user needs, and then to convert this information into technical specifications.

Reference [12] suggests the following tasks to be performed at this early stage:

- Establish design specifications;

- Find information about the project theme;

- Identify the customers' needs;

- Define the customers' requirements ;

- Define project requirements;

- Specify product requirements according to customers needs;

- Establish the product design especifications;

The user requirements (qualitative) and design requirements (quantitative) are an initial reference point for the design team.The Quality Function Deployment (QFD) method is a useful tool for organizing this information. The quality expected by customers can then be mapped with a relationship matrix between user requirements and design requirements, as described by [13].

In Reference [13], it was used the QFD tool to compile learning requirements oriented to e-learning (RLMicracle). Reference [14] presents, as advantages of this tool, the time design reductions and a decreased number of project changes.

Reference [15] Highlights the benefits of using QFD as: quest for continuous quality improvement based on user's desires; design and manufacturing cost reductions, and teamwork.

The development of a Weblab is tightly connected to the context of the didactical experiments to be executed. Its complexity may vary from simple to sophisticated systems, according to the characteristics and requirements took into account in its implementation. The adopted systematic model, shown in Fig. 2, is composed by six phases, where the first two deal with the project planning. The following phases consider three distinct layers denominated physical system, hardware and software, characterizing an integrated engineering process.

The methodology model used in the present case study is depicted in [11] and was based on the concepts of [4]. It considers the multidisciplinary aspects typically existent in this kind of system (WebLabs).

In that model, the first phase is for requirements definition. Some important requirements sources for WebLab's projects were proposed in that model, and contain ideas and contributions inspired in different author's works [16], [17], [18] and [19]. Such requirements sources are not necessarily limited to the extent of the presented list, and were divided into three groups: didactic, technical and end user, as shown in Table I.

The second phase (System Technical Specification), is for the technical specifications definition, which are necessarily measurable and expressible with engineering units.

A set of suggested technical specifications sources for WebLab projects can be seen in Table II.

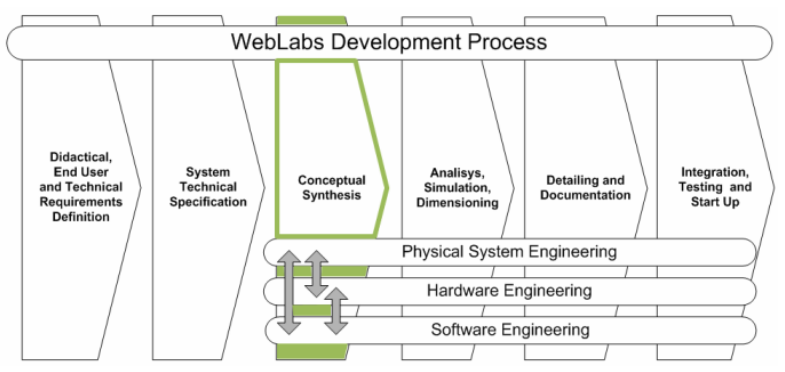

Figure 2. Stage of the Development Process. Mendes [11]

TABLE I.

REQUIREMENTS SOURCES IN WEBLABS’ DESIGNS. MENDES [11].

\begin{tabular}{|c|c|}
\hline Group & Requirements sources \\
\hline Didactical & $\begin{array}{l}\text { Experiments knowledge background } \\
\text { Experiments context and objectives } \\
\text { Didactical sequencing } \\
\text { Commands and results cognition } \\
\text { Expected experiments results }\end{array}$ \\
\hline End User & $\begin{array}{c}\text { Cognitive interface } \\
\text { Dynamic physical system visualization } \\
\text { Interaction modes and elements } \\
\text { User actions guidance } \\
\text { Constant (and enough) system performance } \\
\text { Language options } \\
\text { Multi-platform access } \\
\text { Compatibility with other e-learning systems }\end{array}$ \\
\hline Technical & $\begin{array}{c}\text { Remote experiment setup } \\
\text { Laboratory restrictions } \\
\text { Applicable safety norms and procedures } \\
\text { Experiment data formatting and presentation } \\
\text { Calibration, maintenance and testability } \\
\text { Upgradeability and scalability } \\
\text { Maintainability (local and remote) } \\
\text { Parallelization of tasks } \\
\text { Time availability and use scheduling } \\
\text { User access and permissions management } \\
\text { Support to simultaneous multiple users } \\
\text { Support to collaborative work } \\
\text { Local technician interventions }\end{array}$ \\
\hline
\end{tabular}


TABLE II.

COMMOM SOURCES OF TECHNICAL SPECIFICATIONS IN WEBLABS DESIGNS. MENDES [11]

\begin{tabular}{c}
\hline Sources of Technical Specifications \\
\hline Network connection bandwidth \\
Local and remote computers capabilities \\
Videoconference quality measures \\
Variables ranges and update rates \\
Allowable uncertainties for measured and output signals \\
Experiments limitations and execution times \\
Simultaneous independent or collaborative users \\
Physical system limitations and restrictions \\
Energy usage \\
General safety \\
WebLab availability
\end{tabular}

In the third phase (Conceptual Synthesis) the search for engineering solutions occurs in the three layers described above as physical system, hardware and software.

The following tasks are to be performed at this stage:

- Check the project scope;

- Develop a technical system's design;

- Analyze the design specifications and identify the constraints;

- Establish the system functional structure

- Search for solution principles for each sub-function;

- Select combinations of the solution principles, creating alternative concepts;

- Select the best alternative concept;

- Detail the selected alternative.

In the functional analysis, it is carried out a hierarchical description of the system, beginning with an overall function and then expanding it in the form of a subfunctions tree. At this point, no particular real solutions that could be used to accomplish any or part of the functions should influence the tree construction.

Once defined the functional structure, one can construct the morphological table and systematic search method for deciding the best approach to the solution. In the graph, by combining the solutions to partial functions may be mounted global (or overall) solutions for the entire system. According to [6], the method can be summarized in the application of the following steps: list the characteristics or essential functions to the product; list the ways by which the desired characteristics or functions can be reached; elaborate a table containing the possible solutions; identify the possible combinations of the partial solutions as to arrange global (total) conceptual solutions.

From the global conceptual alternatives assembled, one is to be elected for implementation. An evaluation of performances is carried out using an alternatives comparison and selection method, such as Pugh's, which consists in an evaluation matrix used to rank the candidate solutions with weighted criteria. This ranking method assigns a performance score for each alternative solution being compared, to every criteria defined by the user. The score of each solution is stated by the project development team. The criteria set and their importance weights can be arbitrated or, conveniently, the user requirements and their already stated importances from the QFD step can be used, as in [21] and [22]. In this sense, the solution choice is indirectly driven by the project client's opinions.

By using the above described procedure, the synthesis of a conceptual solution turns into a more rational process.

\section{Designing the Thermal Process Plant WebLab}

The main qualitative and technical / quantitative requirements for this project were brought from a previous work [20], which included the use of House of Quality matrix from the QFD (Quality Function Deployment) method. Ten main user's requirements to be considered along the system development were compiled, as shown in Table III.

A variety of high-level functions are suggested in the reference model [11] to guide the functional structure of a given weblab project. Its adaptation to the present case is shown in the left columns of Table IV.

TABLE III.

USER'S REQUIREMENTS FOR THE THERMAL PLANT WEBLAB. SANTOS [20]

User's Requirements

1- Number (variety) of access devices

2- Access from different operating system

3- User interaction with the equipment

4- User immersion (reality perception)

5- Monitor commands execution

6- Easy to use and operate

7- User management

8- Allow experimental data analysis

9- User's procedures orientation

10- Safety standards

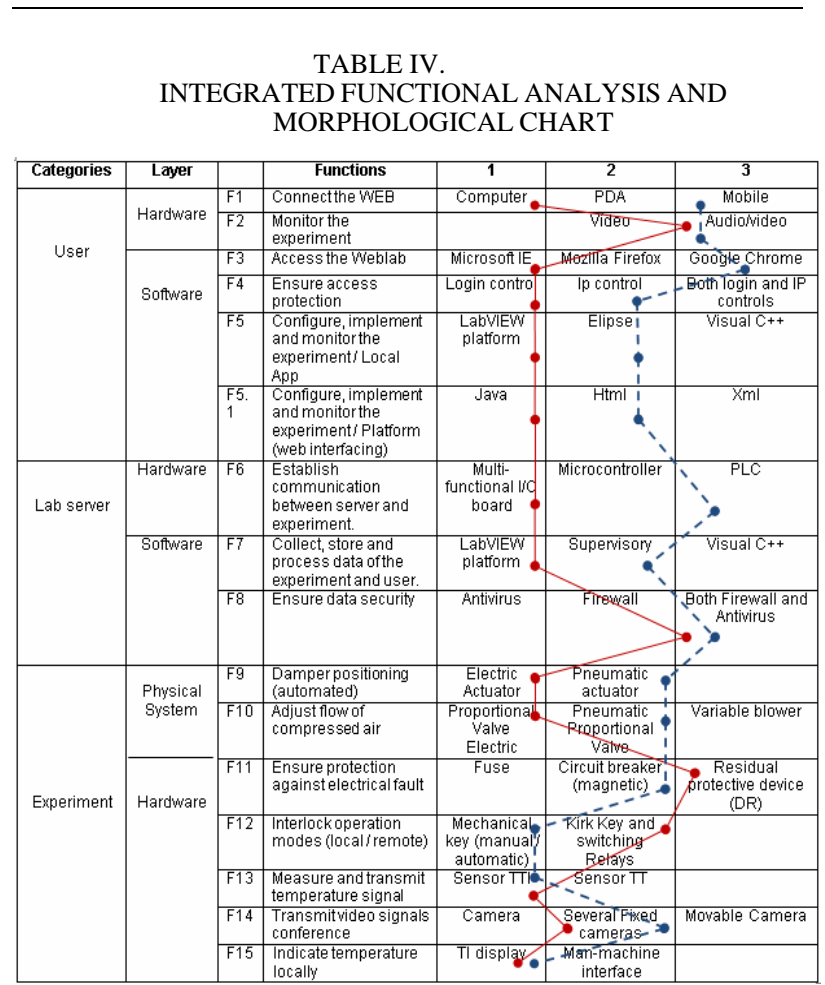




\section{RESUlts}

In order to better organize the information, the functional structure was divided into three categories: User, Lab Server and Experiment.

From the initial global function stated as "Remotely operate the thermal process plant", partial functions were derived and classified in accordance with the belonging layer (hardware, software or physical system). The applicable solution principles to each partial function were organized in the morphological chart, as shown in Table IV.

The collection of solution principles reflects the team experience and research, and contains elements and concepts eventually brought from other projects (e.g. existent WebLabs).

The synthesized solutions are indicated by lines drawn on the morphologic chart, and were designated solutions S1 (red continuous line) and S2 (blue dashed line) respectively.

Through Pugh's method application, shown in Table $\mathrm{V}$, they have been compared. The adopted criteria were the user requirements from the QFD method. The scale used to attribute performance indexes to the alternative solutions was the $1-3-9$, being 1 (lowest performance), 3 (average performance) and 9 (highest performance).

In general terms, both solutions S1 and S2 would be eligible for the Weblab project. The application of Pugh's method demonstrated that solution S1 (784,7 points) presents a higher degree of accomplishment of the criteria than solution S2 (477,0 points). Considering just the question of the remote computational equipment for the Weblab access, in the elected solution S1, the access to the Weblab was defined to be through a personal computer (desktop or notebook), making use of the versatility and higher processing capacity of these equipments. On the other hand, solution S2 was mobility-focused: with the rising availability of the new 3G and $4 \mathrm{G}$ networks, portable devices will offer a growing application potential. A limiting factor by the moment, however, is their yet relative processing and data storage capacities. Another relevant factor in the definitions of the solutions S1 and S2 involve the hardware and the software used to manage and to process the user and the experiment data. The selection of PLCs suggests the use of supervisory software, while the use of multifunctional $\mathrm{I} / \mathrm{O}$ is more likely the choice if the integration will be with a versatile platform such as LabVIEW ${ }^{\mathrm{TM}}$ [23].

Naturally, the elected solution implementation requires adaptations to be made in the existent temperature plant, in order to enable it to operate either locally or remotely whilst reliably and safely. The main additional systems to be integrated to the existent plant are:

A shared server containing:

- I/O multifunctional board with analog and digital inputs / outputs;

- LabVIEW WebServer;

- Firewall and Antivirus;

- Video conference resources;

In the temperature plant itself:

- Residual protective device (DR);

- Interlocking device;
- Visual temperature indicator (TI);

- Damper actuator;

- Air inflow actuator.

At the user side, the resources needed for the remote access and operation, parameters configuration, exhibition, data storage, execution and live visualization of the experiments are:

- Computer with multimedia devices (audio / video) and Internet access;

- Java resources availability;

- Internet explorer browser;

- LabVIEW ${ }^{\mathrm{TM}}$ plug-in.

The integrated concept, as a diagram of the complete elected conceptual solution, is shown in Fig. 3.

TABLE V.

SOLUTIONS OBTAINED THROUGH PUGH'S METHOD.

\begin{tabular}{|c|c|c|c|c|}
\hline Order & Criteria & Importances & S1 & S2 \\
\hline 1 & $\begin{array}{c}\text { Number of access } \\
\text { devices }\end{array}$ & 11,5 & 9 & 3 \\
\hline 2 & $\begin{array}{c}\text { Access from different } \\
\text { operating system }\end{array}$ & 11,5 & 9 & 3 \\
\hline 3 & $\begin{array}{c}\text { User interaction with the } \\
\text { equipment }\end{array}$ & 11,5 & 9 & 9 \\
\hline 4 & $\begin{array}{c}\text { User immersion (reality } \\
\text { perception) }\end{array}$ & 11,5 & 9 & 9 \\
\hline 5 & $\begin{array}{c}\text { Monitor the commands } \\
\text { execution }\end{array}$ & 11,5 & 9 & 9 \\
\hline 7 & Easy to use and operate & 11,5 & 9 & 3 \\
\hline 8 & $\begin{array}{c}\text { Allow experimental data } \\
\text { analysis }\end{array}$ & 11,5 & 3 & 1 \\
\hline 9 & User's procedures & 4,0 & 3 & 1 \\
\hline 10 & orientation & 11,5 & 9 & 3 \\
\hline & Safety standards & 100,0 & 784,7 & 477,0 \\
\hline
\end{tabular}

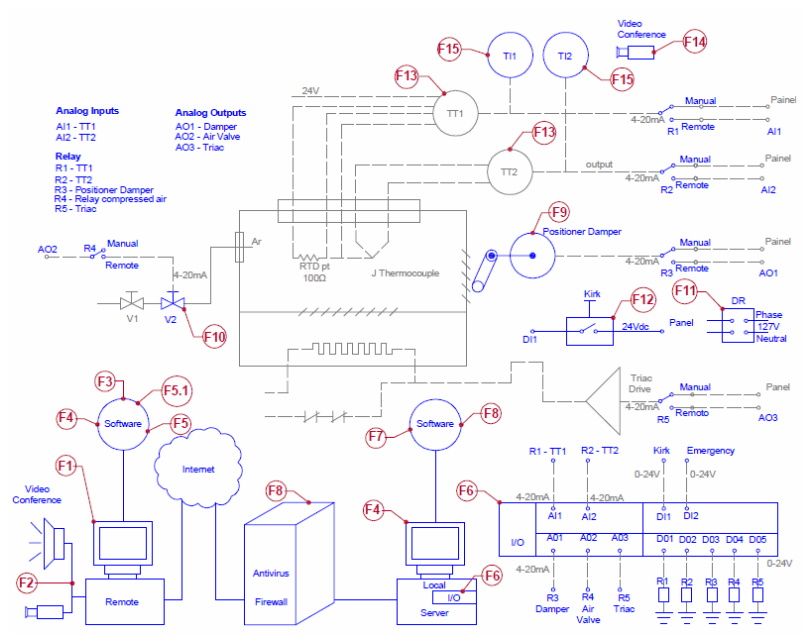

Figure 3. Technical diagram of the selected solution concept, with indication of the solutions adopted for the partial functions. 


\section{SOLUTION DSCUSSION}

The user will access the Weblab from a remote computer connected to the Internet rather using Internet Explorer browser, being necessary the installation of a LabVIEW plug-in. As a security measure, users are required to fill a form with verifiable personal login information and scheduling choices. Once connected, the user has access to the parameters of the selected experiment, as well as to a live transmission of the plant via webcam / microphone located in the laboratory.

The web server hosts the page and plays the following roles: tosecure the access to the experiment; to store the temporary data as well as the user information; to manage a user's agenda; to manage the operation of the temperature plant through the acquisition and transmition of control signals to the actuators, proportional valve, relays and the power TRIAC.

The acquisition and transmition of the input and output signals is performed by $\mathrm{I} / \mathrm{O}$ hardware interfaced to the local computer.

The proportional valve allows the user to vary the air inflow, and so the process loading. In order to produce disturbances, an electrical actuator is connected to the damper. Two temperature indicators (TI) were used, locally and remotely (via webcam) visible.

LabVIEW and Java are the software platforms used in the development of the web interface, as well as for data processing, storage and emailing to the user. The applications and softwares run on Microsoft operational systems. Firewall and antivirus on the server provide the web security.

To guarantee that local and remote operations will not occur simultaneously, a Kirk locking device was included. This device will block the access to the panel connectors, avoiding unauthorized changes while an experiment is running in remote mode. If the Kirk switch is unlocked, the system is automatically switched to local mode. In emergency cases, the electrical power can be switched off by a local switch or a residual protective device (DR).

\section{CONCLUSION}

The adoption of a systematic model based on a functional analysis, followed by alternative solutions assembly using a morphological chart and then by the selection of the most suitable one through Pugh's method, significantly improved the structuration of the activities in the conceptual phase.

The selected solution took advantage of the available pre-existent resources in the lab and in the thermal process plant, aiming the minimization of implementation costs. Standard software and hardware solutions commonly available were prioritized. Furthermore, existent Weblabs architectures studied inspired several options for the fulfillment of the morphological chart.

The obtained results will support the next phase of the systematic model (preliminary design), where the concept general dimensioning and the definition of the final Weblab layout will be carried out.

\section{REFERENCES}

[1] WebLab Deusto. University of Spain, https://weblab.deusto.es/joomla , accessed January, 2012.
[2] RemoteLab FEUP - Faculdade de Engenharia da Universidade do Porto, http://remotelab.fe.up.pt , accessed January, 2012.

[3] Massachusetts Institute of Technology, "MIT iCampus. iLabs: Internet access to real labs - anywhere, anytime", http://icampus.mit.edu/ilabs , accessed January, 2012.

[4] G. Pahl, W.Beitz, "Projeto na Engenharia: Fundamentos de Desenvolvimento Eficaz de Produtos, Métodos e Aplicações”, $6^{\circ}$ ed., Ed Edgard Blucher LTDA., São Paulo, 2005.

[5] N. Back, A. Ogliari, A. Dias, and J. C. da Silva, "Projeto Integrado de Produtos - Planejamento,Concepção e Modelagem”, Ed. Manole, Barueri, São Paulo, 2008, pp.77, pp. 299.

[6] N. Cross, 1994, "Engineering Design Methods, Ed. Wiley”, 2nd. Ed, Chichester, pp. 65-66, pp.108.

[7] VDI 2221, "Methodik zum entwickeln und konstruieren technisher Systeme und Produkte.”, VDI - Verlag, Düsseldorf, 1985.

[8] M. Asimov, "Introduction to design: fundamentals of engineering design”, Prentice Hall, New Jersey, 1962.

[9] ASME Research, "Design theory and methodology: a new discipline”, Mechanical Engineering, 1986, pp.23-27.

[10] N. Back, Metodologia de projeto de produtos industriais. Guanabara Dois, Rio de Janeiro, 1983.

[11] L. A. Mendes, M. L. D. Santos, and M. T. C. Siqueira, "Systematization of the Weblabs Development Process: Towards an Approach Proposal”, International Conference on Engineering Education, ICEE-2010, Gliwice, Poland, 2010, in press.

[12] L. N. Romano, "Modelo de Referência para o processo de Desenvolvimento de Máquinas Agrículas”, Florianópolis, 2003. 266p. Tese (doutorado). PPGEM - UFSC.

[13] D. Cmuk, Mutapcic, T.; and I. Bilic, Miracle - Model for Integration of Remote Laboratories in Courses that Use Laboratory and e-Learning Systems - IEEE Transactions on Learning Technologies, vol. 2, no. 4, october-december 2009

[14] G. Carnevali, and Buttazzo, G., A virtual laboratory environment for real-time experiments. In SISICAS, July, 2003

[15] L. C. Cheng, L. D. R. de Melo Filho, "Desdobramento da Função Qualidade na Gestão de Desenvolvimento de Produtos", Ed. Edgard Blucher, Vol. 1, São Paulo, 2007.

[16] C. Gravier, C., Fayolle, J., Bayard, B., Ates, M., Lardon, J., State of the art about remote laboratories paradigms - foundations of ongoing mutations International Journal of Online Engineering Vol. 4, Issue 1, Feb 2008.

[17] J. García Zubía, Lopez-de-Ipiña, D. Orduña, P. Hernández, U. Trueba. "Questions and Answers for Designing Useful WebLabs”, International Journal of Online Engineering, 2006.

[18] Z. Nedic, Machotka, J., Nafalski, A., Remote Laboratories Versus Virtual and Real Laboratories, 33rd ASEE/IEEE Frontiers in Education Conference, Boulder, 2003.

[19] Prieto-Blázquez, J., Arnedo-Moreno, J., Herrera-Joancomartí, J., "An Integrated Structure for a Virtual Networking Laboratory" IEEE Transactions on Industrial Electronics, Vol. 55, No. 6, June 2008 http://dx.doi.org/10.1109/TIE.2008.921231

[20] M. L. D. Santos, M. T. C. Siqueira, and L. A.Mendes, "Aplicação do QFD no Processo Sistemático de Desenvolvimento de um Weblab para uma Planta de Processo de Temperatura: Identificação dos Requisitos de Usuário e de Projeto", XVII Simpósio de Engenharia de Produção, SIMPEP 2010, Bauru, SP, Brasil, 2010, in press

[21] E. P. Mosconi, M. F. Prim, R. F. Fernandes, and F. A. Forcellini, "Desenvolvimento da Concepção de um Sistema para Gestão de Conhecimento em Pequenas e Médias Empresas de Base Tecnológica”, IV Congresso Brasileiro de Gestão de Desenvolvimento de Produtos, IV CBGDP, Gramado, Rio Grande do Sul, Brasil, 2003.

[22] F. G.Teixeira, R. P. da Silva, T. L. K. da Silva, F. B. Bruno, "Um Sistema WEB para o Projeto Conceitual de Produtos", $5^{\circ}$ Congresso Internacional de Pesquisa em Design, Bauru, São Paulo, Brasil, 2009, in press.

[23] National Instruments - LabVIEW, http://www.ni.com/labview/, accessed January, 2012 


\section{AUTHORS}

M. T. C. de Siqueira, Pontificial Catholic University of Parana (PUC/PR), Production Engineering and Systems, Rua Imaculada Conceição, 1155 (e-mail: marco.siqueira@gmail.com).

M. L. D. dos Santos, Pontificial Catholic University of Parana (PUC/PR), Production Engineering and Systems, Rua Imaculada Conceição, 1155, (e-mail: marcio.debner@gmail.com).
L. A. Mendes, Pontificial Catholic University of Parana (PUC/PR), Production Engineering and Systems, Rua Imaculada Conceição, 1155, e-mail: l.mendes@pucpr.br).

This article is an extended and modified version of a paper presented at the International Conference on Remote Engineering \& Virtual Instrumentation (REV2012), held at University of Deusto, Bilbao, Spain, July 4-6, 2012. Received 15 September 2012. Published as resubmitted by the authors 28 November 2012. 